\title{
Transition from pandemic to infodemic: an analysis of Turkish- language COVID-19 YouTube videos
}

Fatih Cakmak, ${ }^{1}$ Seda Ozkan, ${ }^{1}$ Afsin Ipekci, ${ }^{1}$ Altug Kanbakan, ${ }^{1}$ Turker Demirtakan, ${ }^{1}$ Serap Biberoglu, ${ }^{1}$ Kubra Cakmak, ${ }^{2}$ Nura Fitnat Topbas Selcukii and Turkan Ikizceli ${ }^{4}$

${ }^{1}$ Department of Emergency Medicine, Cerrahpasa Faculty of Medicine, Istanbul University-Cerrahpasa, Istanbul, Turkey. ${ }^{2}$ Clinic of Obstetrics and Gynecology, Esenler Obstetrics and Pediatrics Hospital, İstanbul, Turkey. ${ }^{3}$ Clinic of Obstetrics and Gynecology, Sisli Hamidiye Etfal Training and Research Hospital, İstanbul, Turkey. ${ }^{4} \mathrm{Clinic}$ of Radiology, Health Sciences University, Haseki Training and Research Hospital, Istanbul, Turkey. (Correspondence to: Seda Ozkan: sedacil@gmail.com).

\begin{abstract}
Background: YouTube can be a powerful educational tool for the dissemination of health information. However, if uploaded health-related videos are inaccurate, it can mislead, create confusion and generate panic.

Aims: This study aimed to determine the success of the most-watched Turkish-language COVID-19 YouTube videos regarding information and guidance on the disease for the public. The secondary aim of this study was to evaluate the accuracy and quality of such video content.

Methods: The study was conducted during May 2020 and analysed 133 videos. The length of the videos, the number of likes and dislikes, comments and views, how long they have been on YouTube, Medical Information and Content Index (MICI) Score, mDISCERN scores, global quality scores, and the source and target audiences of the videos were all determined.

Results: The average MICI Scores of videos was $2.48 \pm 3.74$ and the global quality scores was $1.27 \pm 0.64$. When MICI Scores were compared between video sources, the scores of academic hospitals and government videos were significantly higher. The global quality scores of videos from news agencies and independent users was significantly lower $(<0.001)$. The mDISCERN score of the videos uploaded by news agencies and categorized as useful was higher than the others $(P<$ 0.001). Among the targeted videos, only the global quality scores of the videos made for health-care workers were found to be significantly higher.
\end{abstract}

Conclusion: Health-care professionals should upload more videos to improve the quality of health-related video content available on YouTube. Accompanied by evidence-based information, the issues of diagnosis, ways of transmission, prevention and treatment of diseases should be emphasized.

Keywords: COVID-19, pandemic, infodemic, YouTube, Turkey

Citation: Cakmak F; Ozkan S; Ipekci A; Kanbakan A; Demirtakan T; Biberoglu S; et al. Transitıon from pandemıc to infodemı: an analysıs of Turkishlanguage COVID-19 YouTube videos. East Mediterr Health J. 2021;27(5):443-451. https://doi.org/10.26719/emhj.21.011

Received: 24/08/20; accepted: 03/02/21

Copyright (c) World Health Organization (WHO) 2021. Open Access. Some rights reserved. This work is available under the CC BY-NC-SA 3.o IGO license (https://creativecommons.org/licenses/by-nc-sa/3.0/igo)

\section{Introduction}

Coronavirus Disease 2019 (COVID-19), which was first detected in Wuhan, China, in late December 2019, has become one of the most severe pandemics in history. In Turkey, the first COVID-19 case was diagnosed 11 March, 2020, and by 20 May 2020, there were 152587 cases and 4222 deaths reported in the country (1). Common signs of infection are respiratory symptoms, fever, cough, and dyspnea. In more severe cases, pneumonia, severe acute respiratory infection, kidney failure, and even death may develop (2).

COVID-19 related concerns had a rapid impact on the global financial markets and in many industrial sectors with potential long-term consequences (3). In the early stages of the pandemic, some news organizations reported a rapid increase in anti-Asian racism (4-6). Public fears about COVID-19 also led to the panic purchase of consumables, including personal protective equipment, reducing the availability of supplies for health-care professionals (7).

The most effective way to inform the public about COVID-19 is to publish accurate information that is easily accessible and understandable. Google Trends showed a significant increase in interest in COVID-19 since the beginning of February 2020 (8), and the World Health Organization (WHO) has described this excessive information about COVID-19 as an 'infodemia' (9) excessive or unfounded information or news causing fear and panic in society and leading to difficulties in the management of the pandemic. To help mitigate this, WHO works with social media organizations to direct users seeking information about COVID-19 to reliable sources (10). Despite these efforts, during rapidly developing situations the potential to spread inaccurate information through online platforms is high $(11,12)$. YouTube, the second most popular social media platform 
and the world's largest media sharing site, has the highest user numbers following Google, with over 2 billion users. The daily watch time of YouTube is 1 billion hours $(13,14)$.

YouTube's influence in education and information dissemination lies in the quality of its audio and visual communication compared to other social media platforms. Although YouTube is a powerful educational tool that can disseminate health-care professionals' knowledge and influence public behaviour, it can be a misleading, panic-generating, and confusing source of information if misused (15). While appropriate YouTube content may benefit government agencies and healthcare organizations in relieving public anxiety and implementing the measures to control the spread of the disease, the spread of false information can cause paranoia and accelerate the spread of infection (16). Previous studies have shown that YouTube is both a useful and a misleading source of information during public health crises, including the $\mathrm{H} 1 \mathrm{~N} 1$, Ebola, and the Zika outbreaks. These studies have shown that approximately $23 \%$ $26.3 \%$ of YouTube videos are misleading and uploaded by independent users. Accurate, informative and good quality videos do not stand out in these studies (17-19).

Although these studies provide preliminary information on the use of YouTube during public health crises, they have limited adaptability to the COVID-19 outbreak. Current lockdown measures at home have resulted in an excessive increase in YouTube usage. However, there is insufficient evidence in the literature on the quality and accuracy of YouTube content related to the COVID-19 outbreak. Content analysis of social media and online platforms has become an important research topic in recent years. Therefore, the main purpose of this study is to determine the success of the most-watched Turkish COVID-19 YouTube videos regarding information and guidance on the disease for the public. The secondary aim of this study is to evaluate the accuracy and quality of video content.

\section{Methods}

The YouTube social media platform was searched on 20 May 2020 with the Turkish words 'koronavirüs' (coronavirus), 'koronavirus salgını' (coronavirus outbreak), and 'COVID-19 salgını' (COVID-19 outbreak). The first 400 videos found in the search were saved to a playlist in a newly opened YouTube account. Videos with less than 1000 views, videos not in the Turkish language, videos less than 2 minutes or longer than 20 minutes were excluded from the study. Studies show that the length of a quality YouTube video is 10-16 minutes on average, and the average time spent on YouTube is 40 minutes (14). Hence, why video times were limited to 20 minutes in this study. In total, 133 videos meeting the criteria were included. Kappa statistics were used to determine reliability among raters.

The length of the videos, the likes and dislikes they received, the number of comments, the number of views, how long they have been on YouTube, Medical
Information and Content Index (MICI) score, mDISCERN scores, global quality scores (GQS), and the source and target audiences of the videos were determined. Since the duration of the videos available on YouTube affects the number of likes, dislikes, comments and views, video popularity was determined using view ratio, like ratio, and video power index (VPI) parameters. The ratios and indexes were calculated using the following formulas: view ratio: (number of views/number of days since upload); like ratio: (number of like $\times 100 /$ [number of like + number of dislikes]); VPI: [like ratio $\times$ view ratio / 10o] (20).

The source of the videos was news agencies, academic hospitals, government, doctors, and independent users. Health-care professionals and patients/non-health care professionals were accepted as the target audience. The videos were categorized as useful, personal experience, news updates, and misleading. Videos with scientifically correct information about epidemiology, pathogenesis, symptoms, complications, disease prevention, lifestyle changes, and pharmacological treatment were placed in the useful category. Videos that have not been scientifically proven or supported by current guidelines and contain personal propaganda were classified as misleading. Since the diagnosis of coronavirus, videos providing patients' own recollections were grouped in personal experiences. Videos that contain information about the current state of the disease in terms of death and positive cases, and that do not contain information about prevention, treatment or disease prevention measures, were classified as news updates.

The mDISCERN score is a five-question scale adapted from a 16-question DISCERN vehicle developed by Singh (21) and by Charnock, et al (22). Each criterion is rated as 1-0 (yes/no) and scored between 0 and 5. Global quality score is a five-point scale based on the quality of information, the flow of the information supplied online, and ease of use (Table 1). MICI Score examines the video by the subtitles of prevalence, transmission, signs and symptoms, screening tests, and treatment/outcome. Each main category contains five different criteria, resulting in 25 different criteria in MICI. Each criterion is rated as $1-0$ and scored between 0 and 25 (Table 1).

The DISCERN questionnaire is a valid and reliable tool for analysing written consumer health information. It is the first standardized quality index of consumer health information that can be used not only by healthcare professionals but also by patients and the general population as a critical assessment tool to assess health information. Global quality score is a tool for evaluating the overall quality of the site, including information flow, ease of use, and usefulness to patients. The MICI score was developed to evaluate the content quality of videos containing medical information during the Ebola epidemic and was used in studies on COVID-19.

\section{Statistical analysis}

Data statistics were calculated using SPSS 21.0 for Windows (IBM). The suitability of the data to the normal dis- 


\section{Table 1 Global Quality Score, mDISCERN, Medical Information and Content Index (MICI) Score parameters} Global Quality Score
1. Low quality, video information flow weak, most information missing, not beneficial for patients
2. Usually, low quality and low flow of information, some listed information and many important issues are missing, very limited use for patients
3. Moderate quality, the insufficient flow of information, and some important information is sufficiently discussed, but some are poorly discussed and somewhat useful for patients
4. Good quality and generally good information flow. Most of the relevant information is listed, but some topics are not covered, useful for patients
5. Excellent quality and information flow, very useful for patients
mDISCERN score
1. Are the aims clear and achieved?
2. Are reliable sources of information used?
5. Are areas of uncertainty mentioned?
1. Number of confirmed cases reported
2. Number of suspected cases reported
3. Number of reported deaths
4. Number of relevant countries
5. Number / rate of severely ill patients

3. Is the information presented balanced and unbiased?

4. Are additional sources of information listed for patient reference?

\section{Medical Information and Content Index (MICI) Score}

Prevalence: If mentioned in the video, each item is given 1 point. Maximum score 5

Transmission: If mentioned in the video, each item is given 1 point. Maximum score 5
1. The place of origin of the virüs
2. Zoonotic transmission (i.e. contact with animals)
3. Transition from person to person
4. Incubation period
5. Droplet delivery path (includes: mask wearing, hand washing measures)

Signs and Symptoms: If mentioned in the video, each item is given 1 point. Maximum score 5
1. Fever
2. Upper respiratory symptoms (cough, sore throat, runny nose)
3. Lower respiratory symptoms (pneumonia) / shortness of breath)
4. Myalgia, arthralgia, drowsiness
5. Diarrhea

Screening Test: If mentioned in the video, each item is given 1 point. Maximum score 5
1. A testing entity is mentioned
2. Talks about the use of respiratory secretions for testing purposes
3. Mentions that PCR can be used for identification
4. Shows how this test is done
5. Speaks about the criteria for testing/screening
Treatment / Result: If mentioned in the video, each item is given 1 point. Maximum score 5
1. Some patients survive the disease with mild symptoms
2. Some patients become more seriously ill (talk about hospitalization, intensive care)
3. Can be dangerous or cause death
4. Treatment is supportive, but in some cases, HIV drugs are used
5. Vaccine not currently available

tribution was evaluated using the Kolmogorov-Smirnov test. Parametric tests were used since the data were distributed normally. Independent Samples t-test was used to compare two groups, and One-Way ANOVA was used for more than two groups. Post-hoc analysis was per- formed using the Tukey test. Chi-Square tests were used to compare categorical variables. Fisher's Exact test was used if the expected count of cells were less than 5 or the percentage of cells was $>20 \%$. Pearson correlation analysis was used to analyze the correlation between groups. 


\begin{tabular}{|c|c|c|c|c|c|c|}
\hline Characteristics & Useful & $\begin{array}{l}\text { Personal } \\
\text { experience }\end{array}$ & News update & Misleading & Total & $\begin{array}{c}\mathbf{P} \\
\mathbf{X}^{2}\end{array}$ \\
\hline Number of videos & $35(26.31 \%)$ & $30(22.55 \%)$ & $37(27.81 \%)$ & $31(23.33 \%)$ & 133 & \\
\hline Video length (min) & $8.69 \pm 5.15$ & $9.73 \pm 4.95$ & $7.01 \pm 4.06$ & $8.44 \pm 5.36$ & $8.21 \pm 4.93$ & 0.160 \\
\hline View ratio & $4746.88 \pm 14442.69$ & $7196.57 \pm 14899.89$ & $5737.73 \pm 10929.39$ & $5337.06 \pm 6495.97$ & $5747.33 \pm 10846.04$ & 0.876 \\
\hline Like ratio & $93.12 \pm 6.30$ & $95.15 \pm 2.64$ & $88.24 \pm 21.86$ & $93.62 \pm 3.35$ & $92.04 \pm 13.30$ & 0.109 \\
\hline Video power index & $4515.18 \pm 14121.17$ & $6856.25 \pm 14139.68$ & $5072.22 \pm 10393.57$ & $4930.12 \pm 5976.91$ & $5284.11 \pm 10320.42$ & 0.866 \\
\hline MICI Score & $6.77 \pm 6.51$ & $2.43 \pm 2.95$ & $1.83 \pm 2.49$ & $1.87 \pm 3.17$ & $2.48 \pm 3.74$ & $<0.001^{\mathrm{a}}$ \\
\hline Prevalence & $8(6.3 \%)$ & $3(2.3 \%)$ & $3(2.3 \%)$ & $3(2.3 \%)$ & $17(12.8 \%)$ & $\begin{array}{c}0.519 \\
14.084\end{array}$ \\
\hline Transmission & $26(19.6 \%)$ & $14(10.5 \%)$ & $15(11.3 \%)$ & $14(10.5 \%)$ & $69(51.9 \%)$ & $\begin{array}{c}<0.001^{\mathrm{a}} \\
41.751\end{array}$ \\
\hline Clinical symptoms & $14(10.6 \%)$ & $8(6.1 \%)$ & $7(5.4 \%)$ & $4(3.2 \%)$ & $33(\% 24.8 \%)$ & $\begin{array}{l}0.001^{\mathrm{a}} \\
37.643\end{array}$ \\
\hline Screening/tests & $8(6.3 \%)$ & $4(3.1 \%)$ & $2(1.6 \%)$ & $3(2.4 \%)$ & $17(12.8 \%)$ & $\begin{array}{c}0.259 \\
18.067\end{array}$ \\
\hline Treatment/outcomes & $15(11.3 \%)$ & $6(4.6 \%)$ & $8(6.0 \%)$ & $5(3.8 \%)$ & $34(25.6 \%)$ & $\begin{array}{c}0.006 \\
32.026\end{array}$ \\
\hline GQS & $2.45 \pm 1.01$ & $1.23 \pm 0.42$ & $1.08 \pm 0.36$ & $1.12 \pm 0.42$ & $1.27 \pm 0.64$ & $<0.001 a$ \\
\hline mDISCERN score & $2.57 \pm 1.59$ & $1.46 \pm 1.59$ & $2.08 \pm 1.78$ & $1.22 \pm 1.26$ & $1.70 \pm 1.61$ & $0.003 \mathrm{~b}$ \\
\hline \multicolumn{7}{|l|}{ Source of upload } \\
\hline News agencies & 10 & 11 & 32 & 9 & $62(46.6 \%)$ & \multirow{5}{*}{$\begin{array}{l}<0.001^{c} \\
76.369\end{array}$} \\
\hline Academic hospitals & 5 & 0 & 1 & 0 & $6(4.5 \%)$ & \\
\hline Government & 3 & 0 & 0 & 0 & $3(2.3 \%)$ & \\
\hline Physicians & 12 & 2 & 0 & 3 & $17(12.8 \%)$ & \\
\hline Independent users & 5 & 17 & 4 & 19 & $45(33.8 \%)$ & \\
\hline \multicolumn{7}{|l|}{ Target audience } \\
\hline For healthcare providers & 9 & 1 & 0 & 1 & $11(8.3 \%)$ & \multirow{2}{*}{$\begin{array}{c}<0.001^{* *} \\
19.378\end{array}$} \\
\hline $\begin{array}{l}\text { For patients and non- } \\
\text { healthcare workers }\end{array}$ & 26 & 29 & 37 & 20 & $122(91.7 \%)$ & \\
\hline
\end{tabular}

a Significant difference between useful video category and other groups

${ }^{b}$ Significant difference between useful video category and personal experience and misleading groups

'News agencies and independent users are significantly higher than others

\section{Ethical approval}

Since the source of the data is public, institution review board approval was not required.

\section{Results}

The average duration of 133 videos that met the inclusion criteria was $8.4 \pm 4.95$ minutes (min: 2.03 , max: 19.75). The number of likes of the videos was 548281 , and the video with the most likes received 68 ooo. The average number of likes was $4122.41 \pm 9557$. The total number of dislikes of the videos was 28540 , and the video with the most dislikes received 3600 . The average number of dislikes was $214.59 \pm 442.4$. The total number of comments was 78961 , and the video with the most comments received 5218 . The average number of comments was $593.69 \pm 931.64$. The total number of views was 40628198 , and the most watched video was viewed 4922386 times. The average number of views was $305475.17 \pm 611$ 151.4. The videos' availability on YouTube ranged from 4 days to 122 days, with a duration of 7606 days in total and an average duration of $57.19 \pm 26.47$ days.

The level of agreement between researchers was significantly high for both scores (Cohen's kappa: 0.82 for MICI, 0.87 for mDISCERN, and 0.75 for GQS, $P<0.001)$. Useful videos' MICI and GQS scores were significantly higher than other categories $(P<0.001)$. The mDISCERN score of the videos uploaded by news agencies and categorized as useful was higher than the others $(P<0.001)$. Also, the number of information about transmission $(P<0.001)$ and symptoms $(P=0.01)$ in useful videos was higher than other video sources. News agencies and independent users uploaded most of the videos. In addition, the majority of the target audience were patients and non-health care professionals (Table 2).

When MICI scores were compared between video sources, the scores of academic hospitals and government were significantly higher. The GQS of videos from news agencies and independent users was significantly lower $(P<0.001)$. There was no significant difference between the other parameters (Table 3). 


\begin{tabular}{|c|c|c|c|c|c|c|}
\hline Characteristics & News agencies & Academic hospitals & Government & Physicians & $\begin{array}{l}\text { Independent } \\
\text { users }\end{array}$ & $\boldsymbol{P}$ \\
\hline Number of videos & $62(46.61 \%)$ & $6(4.51 \%)$ & $3(2.25 \%)$ & $17(12.78 \%)$ & $45(33.83 \%)$ & \\
\hline Video length (min) & $6.98 \pm 4.46$ & $8.63 \pm 6.07$ & $11.34 \pm 6.98$ & $10.09 \pm 4.50$ & $9.46 \pm 5.17$ & 0.077 \\
\hline View ratio & $5972.57 \pm 9715.17$ & $13577.36 \pm 32987.72$ & $116.28 \pm 100.07$ & $2991.47 \pm 4154.48$ & $5707.01 \pm 12926.48$ & 0.404 \\
\hline Like ratio & $90.40 \pm 17.4$ & $97.29 \pm 2.47$ & $93.77 \pm 7.31$ & $92.97 \pm 6.29$ & $94.01 \pm 3.57$ & 0.503 \\
\hline Video power index & $5425.16 \pm 9214.55$ & $13386.48 \pm 32527.14$ & $110.4 \pm 96.70$ & $2745.45 \pm 3710.71$ & $5345 \cdot 37 \pm 12212.80$ & 0.367 \\
\hline MICI Score & $2.75 \pm 3.62$ & $9.50 \pm 8,01$ & $11.66 \pm 8.38$ & $3.76 \pm 4.89$ & $2.42 \pm 3.93$ & $<0.001^{*}$ \\
\hline GQS & $1.27 \pm 0.60$ & $2.50 \pm 1.37$ & $3.00 \pm 1.00$ & $2.11 \pm 1.05$ & $1.31 \pm 0.66$ & $<0.001^{* *}$ \\
\hline mDISCERN Score & $1.64 \pm 1.65$ & $3.33 \pm 1.86$ & $3.66 \pm 0.57$ & $2.17 \pm 1.62$ & $1.75 \pm 1.58$ & 0.113 \\
\hline
\end{tabular}

${ }^{*}$ MICI scores of academic hospitals and government videos are significantly higher than others

${ }^{* *} G Q S$ score of videos from News agencies and independent users was significantly lower than others

Among the targeted videos, only the GQS of the videos made for health care workers was found to be significantly higher $(P=0.014)$ (Table 4). A positive correlation was found between MICI score, view ratio and VPI, and a negative correlation was observed between like ratio and MICI score. However, these correlations were not statistically significant. A strong positive relationship was detected between MDISCERN and view ratio and VPI, and a negative relationship between like ratio and mDISCERN score. While there was a significant weak negative relationship between GQS and view ratio, a non-significant positive relationship with like ratio and a negative relationship with VPI were detected (Figure 1).

\section{Discussion}

The study results revealed that only $26.31 \%$ of the videos had useful content. Compared to other YouTube content studies, useful video content was found at $61.3 \%$ in a study during the $\mathrm{H}_{1} \mathrm{~N} 1$ outbreak, and $58.6 \%$ in a study conducted in the first months of the COVID-19 outbreak $(17,23)$. The reason for this difference in the useful video content may be that our study included only videos in the Turkish language. In addition, infodemia has grown as people stayed at home for longer periods and shared videos for financial or entertainment purposes without any research aims.
The characteristics of the videos that many people have posted as YouTube content have changed, and many YouTube channels have started to publish videos about the COVID-19 outbreak even though they have no previous knowledge or experience. Accordingly, our study's personal experience video rate was $22.55 \%$, and the misleading video rate was $23.33 \%$. Useful videos' view ratio and VPI were lower than other groups. The reason for this is possibly a lack of popularity of those who want to inform the public by trying to provide accurate information and prevent the spread of the disease. In a YouTube study conducted by Atci et al., the rate of viewing videos and VPIs of misleading categories were found higher than useful content (24). Similarly, a study by Li HO-Y et al. indicated that more than $25 \%$ of YouTube's most viewed English language videos contain misleading information, reaching over 62 million views and about $25 \%$ of total views (25).

Useful videos have significantly higher MICI, mDISCERN, and GQS scores than other groups because these are mostly shared by doctors either directly or via news channels. The reason for the useful video surplus from news channels is that the interviews with doctors are frequently published on YouTube. When we compared the MICI score sub-parameters with other video groups, it could be seen that the clinical symptoms and related transmission scores were significantly higher in the useful video group. These data are similar to the study

\begin{tabular}{lccc}
\hline Table 4 Comparison of video target audiences with scoring and popularity indexes & & \\
& Health-care providers & Patients/non-health care workers & P \\
& & & 0.790 \\
Total MICI Score & $3.63 \pm 5.35$ & $3.24 \pm 4.58$ & 0.226 \\
mDISCERN Score & $2.45 \pm 1.86$ & $1.81 \pm 1.64$ & 0.014 \\
GQS & $2.09 \pm 0.94$ & $1.43 \pm 0.82$ & 0.330 \\
Video length (min) & $7.55 \pm 2.61$ & $8.46 \pm 5.11$ & 0.328 \\
View ratio & $2273.37 \pm 3097.98$ & $6022.75 \pm 12591.50$ & 0.508 \\
Like ratio & $94.72 \pm 3.64$ & $92.12 \pm 12.90$ & 0.344 \\
Video power index & $2107.95 \pm 2834.26$ & $5582.27 \pm 12072.61$ & \\
${ }^{*}$ GQS
\end{tabular}




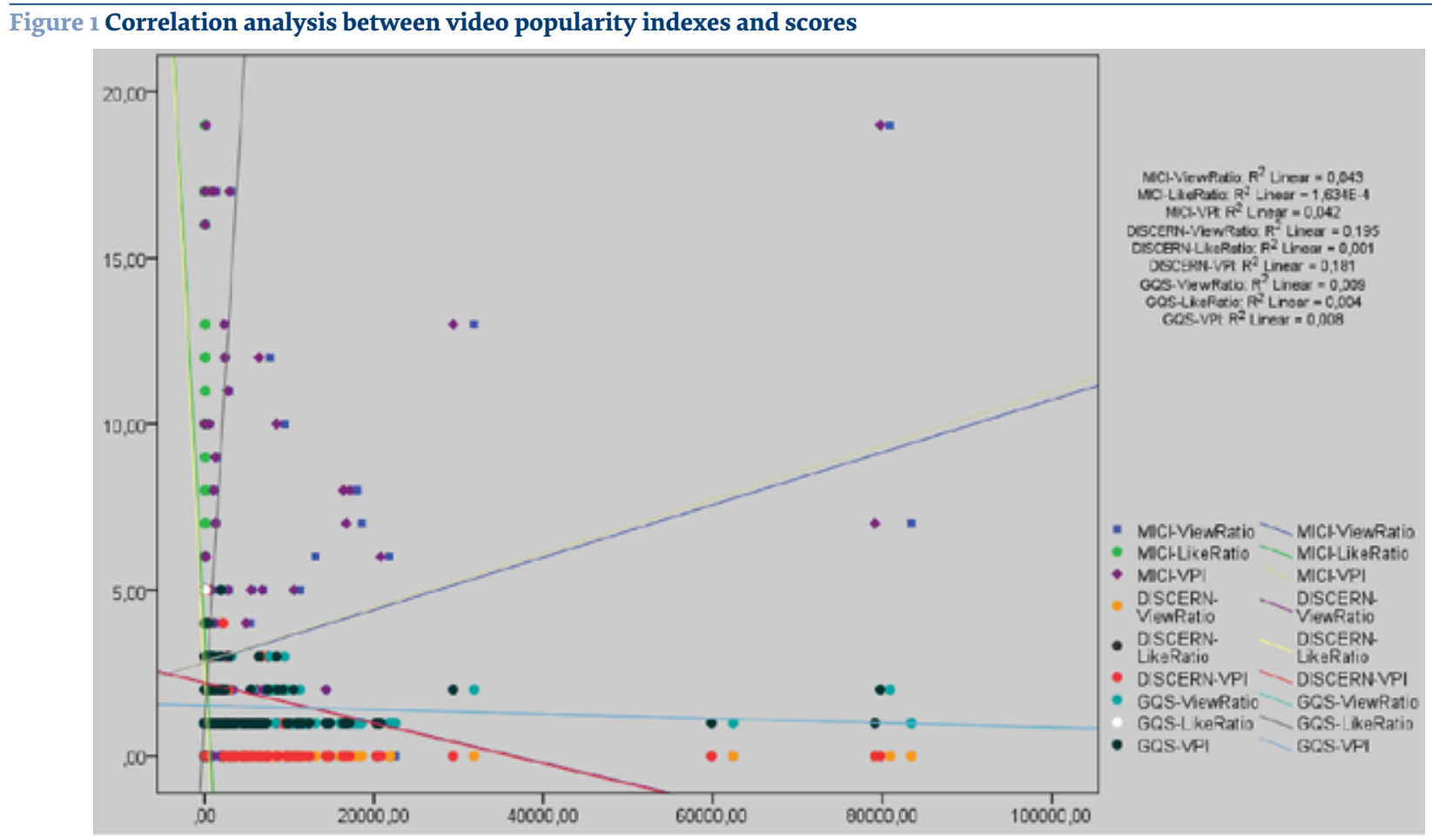

\begin{tabular}{lccc} 
& ViewRatio & LikeRatio & VPI \\
MICI & $0.207^{*}, P=0.017$ & $0.13, P=0.883$ & $0.204^{*}, P=0.018$ \\
MDISCERN & $-0.441^{* *}, P<0.001$ & $-0.037, P=0.688$ & $-0.425^{* *}, P<0.001$ \\
GQS & $-0.095, P=0.278$ & $0.062, P=0.481$ & $-0.089, P=0.310$ \\
\hline
\end{tabular}

*Significant correlation at the level of 0.05 level.

${ }^{* *}$ Significant correlation at the level of 0.01 level.

of P. Khatri et al. on COVID-19 and YouTube (23). The information, which is shared about clinical symptoms and the spread of the disease, requires a medical framework, scientific research, and patient examination. Therefore, it is normal for this type of information to be in the useful video group that is more commonly shared by doctors.

Misleading and personal experience videos are mostly composed of inappropriate content without a scientific basis, so it is quite challenging to access any accurate or reliable information by watching this group of videos. The mDISCERN scores of the videos in the useful and news update groups were significantly higher. The DISCERN score was created to obtain high-quality, evidence-based patient information and to assess the quality of written and visual knowledge about the treatment options of patients and information providers (22).

We saw that only $8.7 \%$ of the videos targeted healthcare professionals when we looked at the videos according to their target groups. Health-care professionals generally refer to evidence-based scientific articles instead of YouTube videos in order to access accurate and quality medical information. However, as a commercial social media platform, YouTube consists of videos that do not have a control mechanism for the accuracy of the content. Thus, a low target rate for health-care professionals would be expected. For this reason, informative videos for health-care professionals cannot find a large audience on YouTube compared to other platforms. Informative videos often do not appear higher on the YouTube dropdown menus or in the foreground, because they do not have enough likes or views.

The number of videos targeting health-care workers was quite low because we included over 1000 viewed videos in the study and most videos targeting healthcare workers were viewed less than 1000. The misleading and personal experience group videos had significantly lower mDISCERN scores. The videos in the personal experience and misleading group consisted mainly of videos disseminating conspiracy theories. Few videos reflected the experiences of people who actually suffered from the disease.

The MICI and mDISCERN scores of the uploaded videos by academic hospitals and government are significantly higher than the other group videos. Because the Ministry of Health, medical faculties and research hospitals have broadcast many informative videos about the treatment protocols, prevention methods, test and confirmed numbers since the first case was detected in Turkey. Accordingly, our findings are similar to the results of the Li Ho-Y et al. study on COVID-19 and YouTube videos (25). On the other hand, some wellknown physicians underestimated the clinical severity of the COVID-19 disease and shared their non-scientific and optimistic predictions at the beginning of the outbreak. 
These physicians lost their credibility in the community after the increase in confirmed cases and death rates, so these uploaded videos are possibly associated with the low MICI and mDISCERN scores.

The videos shared by news agencies and independent users had lower GQS than other videos. GQS is a scale, which tests how much the audiences benefit from the videos and posts shared by unqualified people, which are therefore insufficient in quality. Our results were similar to the findings in the study on YouTube videos about psoriasis misinformation by Qi, J et al (26). Although the videos shared by news agencies and independent users had low GQS, the view ratio and VPI scores were higher than the government and physicians' group. This might be because the videos shared on YouTube channels, which had many followers before the epidemic, reached more people and were watched regardless of their content. Even if the most accurate information is conveyed with the best quality video, it does not reach enough people if there are not enough followers on social media.

As a part of the sociocultural background in Turkey, conspiracy theories prevail. The effects of this can be seen in the view rates of COVID-19 related videos and their contents. This also explains the reason why videos uploaded by freelance users and news agencies have higher view rates regardless of their low content qualities. A substantial part of the Turkish population was found to believe in conspiracy theories rather than evidence-based facts. Therefore, a population with such tendencies watches videos with content that they would prefer to believe in or that interests them rather than contents conveying commonly accepted facts. The lack of ethical boundaries in social media and its desire to get people's attention by creating a sense of panic has been exploited during this pandemic. Although social media sometimes exposes well-hidden secrets, it is also the case that fictional events are presented as facts. The focus on drawing attention and becoming a trending topic of media organizations can lead them to convey the news in a way which causes population-wide panic. In addition to television and newspapers, social media is a news platform relatively trusted by the greater population. However, the importance attributed to view rates and recognition by this platform leads to the sharing of videos with nonfactual or inaccurate content $(27,28)$.

\section{Conclusion}

Health-care professionals should upload more videos to improve the quality of YouTube's health-related video content. Accompanied by evidence-based information, the issues of diagnosis, means of transmission, prevention, and treatment of diseases should be emphasized. Individual channels about health should be encouraged and the awareness of their existence increased. Adding a YouTube academic tab, where videos are reviewed and criticized by editor control, as in Google Academic, will both increase the use of YouTube by health-care workers and make it easier for the public to access more accurate information. The videos could indeed be evaluated by volunteer health professional referees.

Funding: None.

Competing interests: None declared.

\section{De la pandémie à l'infodémie : analyse de vidéos YouTube turques sur la COVID-19 Résumé}

Contexte : YouTube peut être un puissant outil pédagogique pour la diffusion de l'information sanitaire. Cependant, si les vidéos liées à la santé postées présentent des informations inexactes, elles peuvent induire en erreur, créer de la confusion et générer la panique.

Objectifs : La présente étude visait à déterminer la pertinence des vidéos YouTube sur la COVID-19 en langue turque les plus visionnées eu égard à l'information et l'orientation du public sur la maladie. L'objectif secondaire de cette étude était d'évaluer l'exactitude et la qualité de ces contenus vidéo.

Méthodes : L'étude a été menée en mai 2020 et a analysé 133 vidéos. La longueur des vidéos, le nombre de «j’aime ce contenu » et de «je n'aime pas ce contenu », de commentaires et de vues, la durée de leur présence sur YouTube, le score MICI (Medical Information And Content Index), les scores DISCERN moyens, les scores de qualité globale, ainsi que la source et les publics cibles des vidéos ont tous été déterminés.

Résultats: Les scores MICI moyens des vidéos étaient de 2,48 $( \pm 3,74)$ et les scores de qualité globale étaient de $1,27( \pm 0,64)$. Lorsque les scores MICI ont été comparés entre les sources des vidéos, les scores des hôpitaux universitaires et des vidéos gouvernementales étaient nettement plus élevés. Les scores de qualité globale des vidéos des agences de presse et des utilisateurs indépendants étaient significativement plus faibles $(p<0,001)$. Le score DISCERN moyen des vidéos postées par les agences de presse et classées comme utiles était plus élevé que les autres $(p<0,001)$. Parmi les vidéos ciblées, seuls les scores de qualité globale des vidéos réalisées pour les professionnels de santé se sont avérés significativement plus élevés.

Conclusion : Les professionnels de santé devraient mettre en ligne davantage de vidéos pour améliorer la qualité $\mathrm{du}$ contenu sur la santé disponible sur YouTube. Les questions du diagnostic, des modes de transmission, de la prévention et du traitement des maladies devraient être mises en exergue tout en apportant des informations fondées sur des données probantes. 


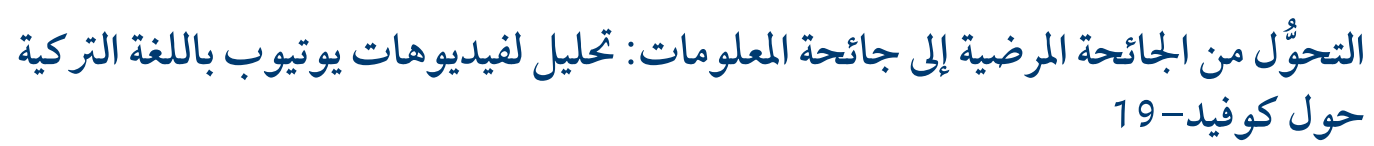

فاتح كاكماك، سيدا أوزكان، أفسين إيبكتشي، ألتوج كانباكان، توركر ديمرتاكان، سراب بيبيروجلو، كوبرا كاكماك، نورا سيلكوكي، تركان إيكيزيللي

الخلاصة

الخلفية: يمكن أن يكون موقع يوتيوب أداةً تعليميةً قويةً لنشر المعلومات الصحية، لكن إذا نُشرت مقاطع فيديو صحية غير دقيقة، فقد تؤدي إلى

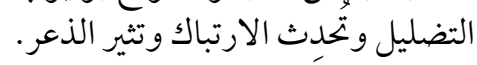

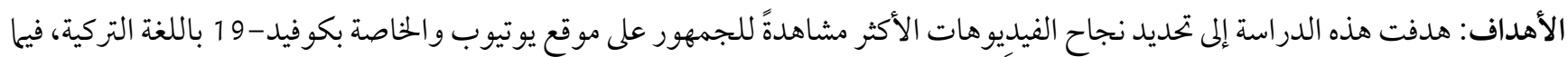

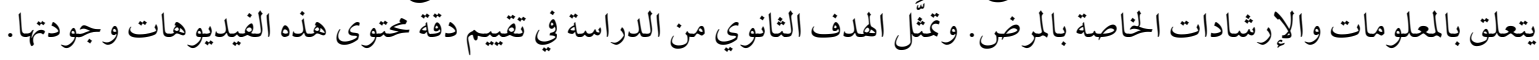

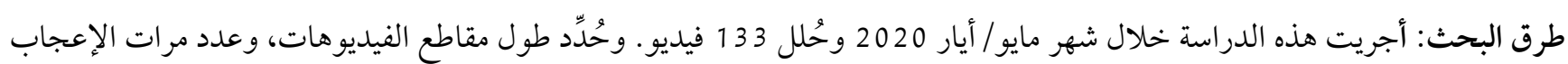

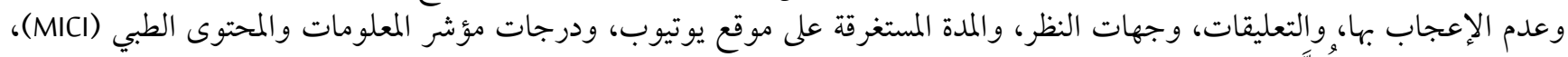

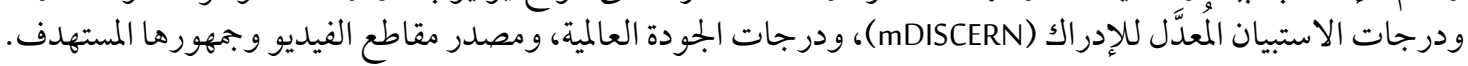

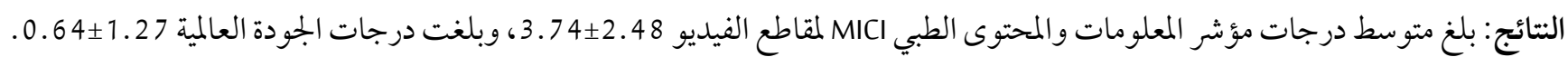

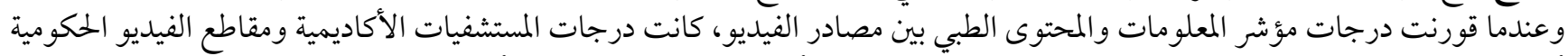

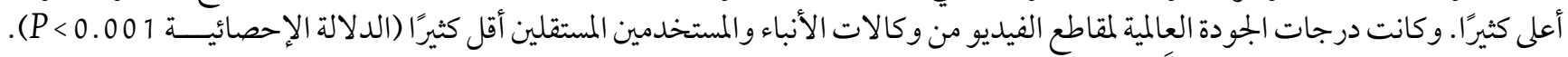

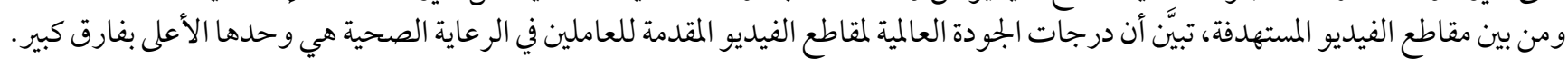

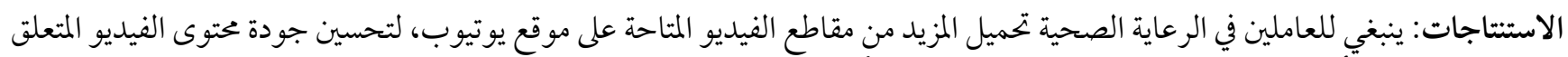

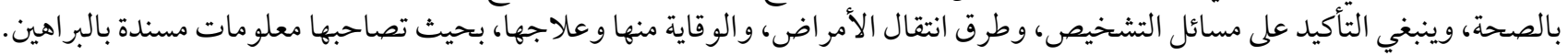

\section{References}

1. World Health Organization. Coronavirus disease 2019 (COVID-19) situation report - 122. Geneva: World Health Organization; 2020 (https://www.who.int/docs/default-source/coronaviruse/sittion-reports/20200521-covid-19-sitrep-122.pdf?sfvrsn=24f20e05_2).

2. Turkish Ministry of Health. Directorate General of Public Health COVID-19 (Sars-Cov-2 Infection) Guide. Ankara: Ministry of Health; 2020 (https://hsgm.saglik.gov.tr/depo/birimler/goc_sagligi/covid19/rehber/COVID19_Rehberi20200414_eng _ v4_002_14.05.2020.pdf, accessed 22 May 2020)

3. David Y, Stanley R, Matt P, Niraj C, Tiffany H, Sapna M. Stocks plunge again on coronavirus fears. The New York Times, 5 March 2020 (https://www.nytimes.com/2020/03/05/business/stock-market-covid-19.html).

4. Escobar N. When xenophobia spreads like a virus. NPR, 4 March 2020 (https://www.npr.org/transcripts/811363404).

5. Haynes S. As coronavirus spreads, so does xenophobia and anti-Asian racism. Time, 6 March 2020 (https://time.com/5797836/ coronavirus-racism-stereotypes-attacks/, accessed 22 May 2020).

6. Pan D. Fears of coronavirus fuel anti-Chinese racism. Boston Globe, 30 January 2020 (https://www.bostonglobe.com/2020/01/31/ metro/fears-coronavirus-fuel-anti-chinese-racism/).

7. World Health Organization. Shortage of personal protective equipment endangering health workers worldwide. Geneva: World Health Organization; 2020 (https://www.who.int/news-room/detail/03-03-2020-shortage-of-personal-protective-equipment-endangering-health-workers-worldwide, accessed 22 May 2020).

8. Google Trends. COVID-19. (https://trends.google.com/trends/explore?geo=TR\&q=COVID-19, accessed 22 May 2020).

9. Zarocostas J. How to fight an infodemic. The Lancet 2020;395:676.

10. Duffy C. How health officials and social media are teaming up to fight the coronavirus 'infodemic'. CNN, 1 March 2020 (https:// edition.cnn.com/2020/03/01/tech/coronavirus-social-media-reliable-sources/index.html).

11. Homeland Security. Countering false information on social media in disasters and emergencies. Washington DC: Homeland Security; 2018 (https://www.dhs.gov/sites/default/files/publications/SMWG_Countering-False-Info-Social-Media-Disasters-Emergencies_Mar2018-508.pdf).

12. World Health Organization. Coronavirus disease 2019 (COVID-19) situation report - 45. Geneva: World Health Organization; 2020 (https://www.who.int/docs/default-source/coronaviruse/situation-reports/20200305-sitrep-45-covid-19.pdf?sfvrsn=ed2ba78b_2, accessed 22 May 2020).

13. Alexa. The top 500 sites on the web. (https://www.alexa.com/topsites, accessed 22 May 2020).

14. YouTube. YouTube for press. (https://www.youtube.com/about/press/, accessed 22 May 2020). 
15. Rabee R, Najim M, Sherwani Y, Ahmed M, Ashraf M, Al-Jibury O, et al. YouTube in medical education: a student's perspective. Med Educ Online 2015;20:29507 https://doi.org/10.3402/meo.v20.29507

16. Gonsalves G, Staley P. Panic, paranoia, and public health - the AIDS epidemic's lessons for Ebola. N Engl J Med. 2014;371:23482349. doi:10.1056/NEJMp1413425

17. Pandey A, Patni N, Singh M, Sood A, Singh G. Youtube as a source of information on the HiN1 influenza pandemic. Am J Prev Med. 2010;38:e1-3.

18. Pathak R, Poudel DR, Karmacharya P, Pathak A, Aryal MR, Mahmood M, et al. YouTube as a source of information on Ebola virus disease. N Am J Med Sci. 2015;7:306-9.

19. Bora K, Das D, Barman B, Borah P. Are internet videos useful sources of information during global public health emergencies? A case study of YouTube videos during the 2015-16 Zika virus pandemic. Pathog Glob Health. 2018;112:320-8.

20. Erdem MN, Karaca S. Evaluating the accuracy and quality of the information in kyphosis videos shared on YouTube. Spine, 2018;43:E1334-9.

21. Singh AG, Singh S, Singh PP. YouTube for information on rheumatoid arthritis - a wakeup call? J Rheumatol. 2012; 39:899-903.

22. Charnock D, Shepperd S, Needham G, Gann R. DISCERN an instrument for judging the quality of written consumer health information on treatment choices. J Epidemiol Community Health. 1999;53:105-11.

23. Khatri P, Singh S, Belani NK, Leng YY, Lohan R, Wei L, et al. YouTube as a source of information on 2019 novel coronavirus outbreak: a cross-sectional study of English and Mandarin content. Travel Med. Infect. Dis. https://doi:10.1016/j.tmaid.2020.101636.

24. Atci AG, Atci IB. Quality and reliability of information available on YouTube videos pertaining to transforaminal lumbar epidural steroid injections. Romanian Neurosurgery. 2019;33:299-304.

25. Li Ho-Y, Bailey A, Huynh D, Chan J. YouTube as a source of information on COVID-19: a pandemic of misinformation? BMJ Global Health. 2020;5:e002604. doi:10.1136/bmjgh-2020-002604

26. Qi J, Trang T, Doong J, Kang S, Chien A. Misinformation is prevalent in psoriasis-related YouTube videos. Dermatology Online Journal 2016; 22(11). (https://escholarship.org/uc/item/7qc9z2m5).

27. Yıldırım, S. Social-psychological view of the epidemics: COVID-19 (corona virus) pandemic case. Turkish Studies, 15(4), 1331-1351. https://dx.doi.org/10.7827/TurkishStudies.43585

28. Baydili, İ. Comparison of doctor videos on YouTube with WHO and Turkish Ministry of Health discourses during COVID-19. Turkish Studies. 2020;15(4):153-178. https://dx.doi.org/10.7827/TurkishStudies.44188 